\title{
The Solution for Variation of Renewable Energy Generation
}

\author{
Lessen from solar eclipse in Germany
}

\author{
Weizheng Kong*, Yunqi Zhao, Lin Liu, Lu Xing and Dong Zhang \\ State Grid Corporation of China, Future Technology City, Beijing, 102-209, China \\ ${ }^{*}$ Corresponding author
}

\begin{abstract}
The renewable energy generators have the feature that varies as weather changes. The fluctuation of the power output will break the balance of supply and demand among the electric power grid, bringing risk to the whole power system. In March 20, 2015, total solar eclipse caused a sudden drop and then a surge in solar-generated power that is balanced out to avoid instability in the grid. The accuracy forecasting and abundant spinning reserve capacity as well as the coordinated ENISO-E power grid helped the Germany handle the power fluctuation caused by solar eclipse.
\end{abstract}

Keywords-renewable energy; solar eclipse; bulk power grid; power forecasting

\section{INTRODUCTION}

From 9.33 am to 11.52 am in March 20, 2015, a total solar eclipse hit the whole territory of Germany. It could be a amazing time for most of the people except the ones who operated the electric power grid and took charge of the power system security. Among the 180GW installed generating capacity, there was about 38GW photovoltaic(PV) solar power $^{[1]}$. If all the solar PV systems worked as usual, the eclipse would cause a sudden drop 20 percent or more in solar output at a time of day when output typically climbs steeply ${ }^{[2]}$. After this dip, there will be a sudden, sharp increase in solar output. Worse more, most of the solar PV are on the roof top as the distributed generation ${ }^{[3]}$, out of control from the independent system operator(ISO), who had the ability to adjust the portfolio of output from varies power resource which are under control of ISO ${ }^{[4]}$. Therefore, it provided a fascinating challenge facing electric grid that conventional power plants would have to run in order to compensate for the dip in solar generation, leading to higher prices ${ }^{[5]}$.

\section{POWER FLUCTUATION IN SOLAR ECLIPSE DAY}

At 7 am March 20 before solar eclipse, everything went well as the output of PV rose up from 70MW. At 9.45 am, PV reached $13 \mathrm{GW}$ as its peak , then the impact of solar eclipse began to occur, resulting the dropping down of PV output curve. At 10.45 am, PV generated at the bottom of 4.8GW. When the eclipse ended, the PV generation climbed to $19 \mathrm{GW}$ at $11.50 \mathrm{am}^{[6]}$ The decline in output was 2.7 times faster than a normal production decline, but solar output then increased up to 3.5 times faster than normal, immediately after the eclipse ends $^{[6]}$, although the change rate of power supply was not so fast as people expect,.

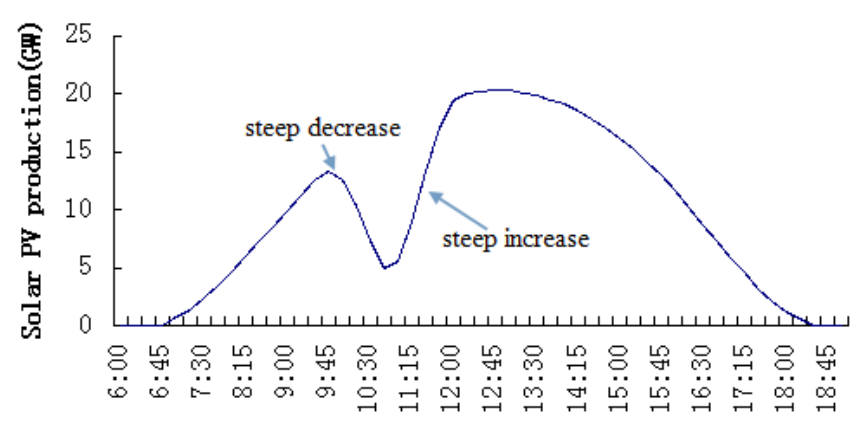

\section{FIGURE I. POWER OUTPUT OF SOLAR PV GENERATION.}

It was unexpected that the electric spot price did not jump to a high level due to the lack of solar power supply. The average electric price was $€ 38.5$ per MWh through the eclipse period, only 10 percent higher than the last day. After the solar eclipse, the market price of electricity come back to normal. ${ }^{[7]}$

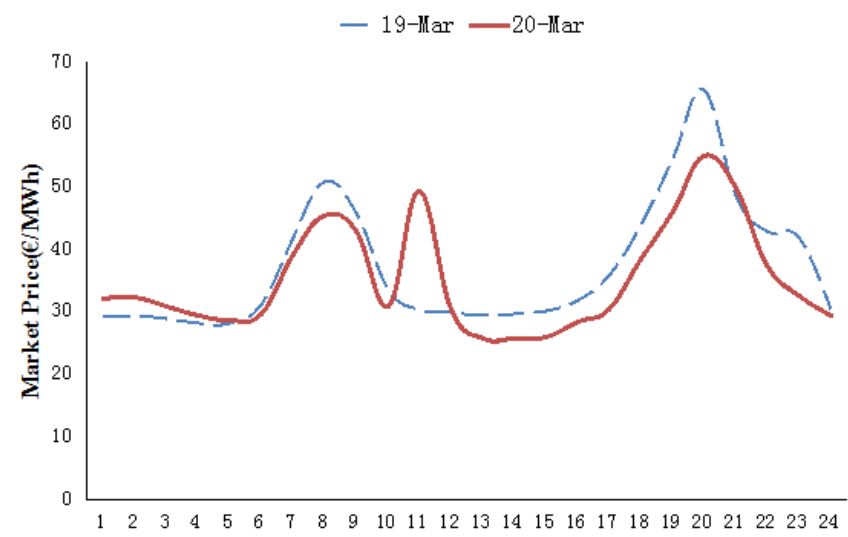

FIGURE II. MARKET PRICE OF ELECTRICITY.

\section{STRATEGY FOR POWER FLUCTUATION}

Several months in advance of the March 20, 2015, the European Network of Transmission System Operators for Electricity (ENTSO-E) began evaluating the risk to Europe's power grid. ${ }^{[8]}$ When the eclipse hits and solar power supply starts to tumble, German energy providers and grid operators responded with a combination of strategies. 


\section{A. Precise Solar Power Forecasting}

To avoid the unexpected sudden drop of power supply, the Germany's power grid operators used the state of art forecasting technology to stimulate the PV performance under the solar eclipse. As figure III shows, the forecast and actual power output curves of solar PV are very close not only in the up and down trend, but also in the amplitude of load curves of which the error was less than 2 percent to total generating capacity. Based on the precise forecasting result, system operators could arrange other power generators to increase or decrease their production to compensate for the dip in solar generation.

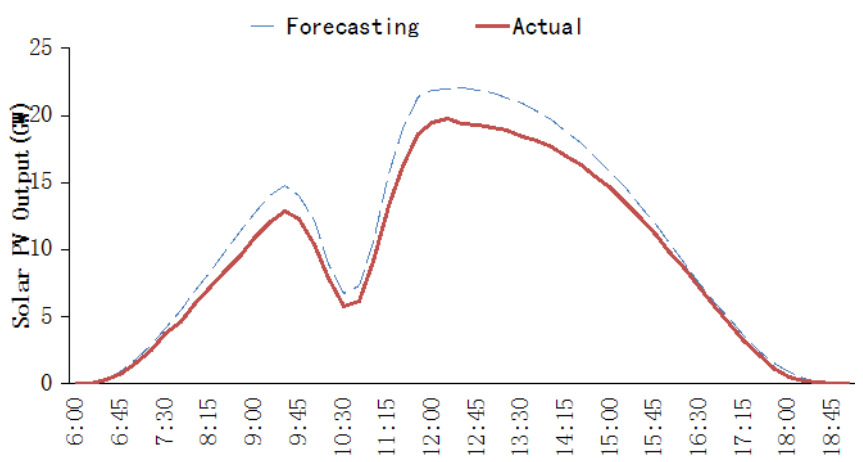

FIGURE III. FORECASTING AND ACTUAL SOLAR PV OUTPUT.

The solar power forecasting company and four German power grid operation companies as well as European Network of Transmission System Operators for Electricity(ENTSO-E) had prepared for the challenge of solar eclipse for several months. The forecasting company Energy\&Meteo Systems gave out several solar power output curves in different climate scenarios a few months before the eclipse based on the history data and updated the forecasting results according to the weather report. The grid operator considered the worst case that maxim drop-off and spike rate, according to forecast, are 281MW per minute and 169MW per minute, which are 2 times steeper than the actual ramp up and down rate.

\section{B. Abundant Flexible Generating Capacity}

To handle the heavy power fluctuation, the transmission system operators(TSOs) of Germany prepared more spinning reserve capacity than usual. In March 20, 2.3GW negative and 2.2GW positive secondary reserve capacity were on standby to regulated with unexpected sudden change of power supply. There was 34GW of hydro with reservoir and quick-start gasfired thermal power stations, which were flexible enough to smooth the big wave of power output curve. When the output of solar PV dropped down by $4.8 \mathrm{GW}$ and load got up by 2.2GW between 9 am and $10 \mathrm{am}$, the pumped storage stations increased $1.3 \mathrm{GW}$ generation and thermal power stations increased $0.7 \mathrm{GW}$ to meet the gap of supply and demand.

\section{Strong Interconnection of the Power Grid in ENTSO-E}

Germany's electric power grid allocates in the center of whole European network, having strong back up from other counties. It was easy to exchange power with other European counties that when the power supply exceeds the demand the power can be transmitted outside Germany, otherwise in the opposite direction. In the period of solar eclipse, as the net generating capacity declined $6.9 \mathrm{GW}$, the electricity export dropped down by $4.7 \mathrm{GW}$ at the same time, contributing $68 \%$ of mitigating the supply and demand gap. At the end of the eclipse, the electricity export rose up 3.7GW, contributing 49 percent of reducing the effect of net generating capacity increasing 7.6GW.

\section{LESSONS FROM GERMAN SOLAR ECLIPSE}

The installed capacity of solar PV took 22 percent of total generating capacity in German. It was supposed that the solar eclipse would brought a big trouble to the power system, however, the power frequency and system security as well as the electricity price were not be affected much. The lessons from the German successfully passing the severe threat from total solar eclipse could be summed as bellow:

\section{A. European Bulk Power Grid}

The bulk power grid has the ability to balance the supply and demand in a wider area. In the Germany's case, over 50 percent of the net load change was offset by the interconnection transmission lines between Germany and around counties. Beside, a wider power grid covers a larger space of renewable energy, which abates the fluctuation of power output in each separated place. the The more renewable energy power the power grid connected, the smoother the power output is in the power system view.

\section{B. Renewable Energy Forecasting}

It is wise to forecast the power output of renewable energy before the severe events such as solar eclipse, strong wind, or heavy cloud. In this case, system operators prepared for the worst and accepted the simulation result of lowest power output during the total solar eclipse as well as the fastest ramp rate in the whole process. In fact, the situation was not as poor as expectation, so it could be easier for the operators to solve the eclipse condition and keep the system security.

\section{Reasonable Generation Mix}

Besides the bulk power grid and precise forecasting, the reasonable generation mix also played an important roll in prevent the system collapse from heavy power fluctuation caused by renewable energy generation. Hydro power with reservoir and quick-start gas-fired power stations have the ability to change the generated output in a short time, eliminating the fluctuation effect of renewable generation.

\section{CONCLUSION}

When total solar eclipse hit German in March 20, 2015, the Germany's power system which has 22 percent of solar PV, had passed through this tough time easily. The successful experience of accommodating high penetration renewable energy can be attributed to bulk power gird balance, precise solar power forecasting and reasonable generation mix. For the other counties with plentiful renewable energy, it is advisable to expand and reinforce the power grid, improve the renewable power forecasting and install more flexible generating capacity. 


\section{ACKNOWLEDGMENT}

In the process of composing this paper, Dr. Caixia Wang gives many academic and constructive advice, and helps double checking the paper.

\section{REFERENCES}

[1] EPIA. Global market report for Photovoltaics 2014-2018. 2015.

[2] Liu Chun, Ma Shuo, Dong Cun, Huang Yuehui, Wang Yuefeng, et al. Review and Experiences of the European Solar Eclipse's Impact on Power Grid Operation With Significant PV Generation. Power System Technology, 2015,7:1765-1772

[3] Stetz, T., von Appen, J., Niedermeyer, F., Scheibner, G., Sikora, R., Braun, M. Twilight of the Grids: The Impact of Distributed Solar on Germany’s Energy Transition. Power and Energy Magazine, 2015, 13: 50 - 61

[4] Phulpin, Y.; Begovic, M.; Ernst, D. Coordination of voltage control in a power system operated by multiple transmission utilities. Bulk Power System Dynamics and Control (iREP) - VIII (iREP), 2010 iREP Symposium, 2010:1-8

[5] Albuyeh, F. Integration of variable generation resources into control center operations. Power and Energy Society General Meeting, 2010: 1

[6] SMA Company's official website, performance of photovoltaic (PV) in Germany[EB/OL]. [2015-04-25]. http://www.sma.de/en/company/ pvelectricity-produced-in-germany.

[7] EEX. http://www.eex-transparency.com/homepage

[8] Regional Group Continental Europe and Synchronous Area Great Britain of ENTSO-E. Solar eclipse 2015 impact analysis[R]. Brussels, Belgium: The Entso-e, 2015 